\title{
Pengaruh Investasi Dan Tenaga Kerja Terhadap Produksi Pada Industri Kecil di Kabupaten Aceh Utara
}

\author{
Khairil Anwar ${ }^{* a}$, Muhammad Yani Saputra ${ }^{* b}$ \\ * Fakultas Ekonomi dan Bisnis Universitas Malikussaleh \\ a Corresponding author:khairil.anwar.semsi@gamil.com
}

ARTICLE INFORMATION ABSTRACT

Keywords:

Investment, Labor, Small

industrial production
This research focuses on the effect of investment, labor, on production in small industries in North Aceh Regency. The study uses secondary data 2010-2016. The method of data analysis in this observation is a multiple linear regression method. The results show that investment and labor have a significant and positive effect on small industrial production in North Aceh Regency.

\section{PENDAHULUAN}

Provinsi Aceh merupakan provinsi paling barat di Indonesia yang terkenal akan berbagai keberagaman daerah nya, maupun dari segi bahasa, adat istiadat,budaya, serta potensi pariwisata yang baik, dan yang menjadi pusat perhatian terhadap Provinsi ini adalah Sumber Daya Alam nya yang begitu melimpah seakan-akan tidak pernah habis. Baru-baru ini ditemukan sumber daya migas terbesar di dunia di Provinsi aceh yang diperkirakan melampaui migas Arab Saudi.

Salah satu kabupaten di Provinsi Aceh yang fokus untuk mengembangkan sektor industri adalah Kabupaten Aceh Utara. Kabupaten Aceh Utara yang dikenal sebagai salah satu daerah industri besar seperti PT. Pupuk Iskandar Muda (PIM) dan beberapa lainnya. Dengan adanya industri besar di Kabupaten Aceh utara diharapkan bisa diikuti oleh pertumbuhan industri kecil.

Dari data yang ada tahun 2014 usaha kecil formal sedikitnya 1.783 unit dengan serapan tenaga kerja mencapai 5.914 orang. Dalam waktu beberapa tahun terakhir di Kabupaten Aceh Utara mengalami pertumbuhan industri kecil yang sangat berubah-ubah, bahkan pada tahun 2016 mengalami penurunan yang sangat buruk yaitu jumlah unit usaha yang menurun yang hanya berjumlah 346 unit, sehingga penyerapan tenaga kerja menurun secara drastis, yang hanya berjumlah 1.754 orang.
Hal ini sangat berpengaruh terhadap produksi industri kecil Aceh Utara.

Seharusnya keberhasilan pelaksanaan investasi yang terdapat pada wilayah lain bisa di laksanakan di daerah yang berpotensi industri seperti kabupaten Aceh Utara. Kabupaten Aceh Utara sebagai daerah yang masih dalam proses pembangunan mengalami berbagai permasalahan. Di antara persoalan yang tampak yaitu jumlah angkatan kerja meningkat namun tidak berbanding lurus dengan pertumbuhan sektor pembangunan (Mukmin, 2013).

Investasi yang besar terhadap sektor industri harus diwujudkan agar dapat membuka lapangan kerja yang lebih luas dan membutuhkan tenaga kerja yang sangat banyak seperti yang diharapkan. Untuk memecahkan masalah pengangguran untuk masa depan maka diperlukan penyaluran pendapatan daerah tersebut kepada masyarakat dalam bentuk terbukanya lapangan kerja produktif. Terciptanya lapangan pekerjaan membutuhkan dana investasi yang lumayan besar jumlahnya hal ini akan memberikan kesempatan terhadap tenaga kerja akan lebih banyak.

Jaminan keamanan dan biaya investasi produktif juga akan meningkatkan investasi internasional maupun domestik (Darmadi, 2011). Untuk mendapatkan Produksi maksimum di sektor industri, perlu adanya peningkatan investasi. 
Investasi adalah salah satu penentu pertumbuhan ekonomi, karena dengan adanya invetasi dapat menaikkan output secara signifikan, hal ini dengan sendirinya berfungsi meningkatkan permintaan terhadap input, sehingga kesejahteraan serta lowongan kerja meningkat bagi masyarakat dan akan meningkatkan pendapatan masyarakat (Amelia, 2017)

Tujuan pada penelitian ini adalah untuk mengetahui seberapa besar pengaruh investasi dan tenaga kerja terhadap produksi industri kecil di Aceh Utara.

\section{TINJAUAN TEORITIS}

\section{Produksi}

Definisi Produksi Menurut (Fauzi Ramadhan, 2016) produksi adalah suatu upaya untuk membuat atau meningkatkan fungsi barang. Agar bisa melakukan proses produksi, orang tentu memerlukan tenaga kerja, bahan baku, modal dalam berbagai bentuknya serta keahlian tertentu. Semua unsur-unsur tersebut disebut dengan faktorfaktor produksi. Sedangkan produksi merupakan aktivitas untuk menaikkan guna suatu barang.

Produksi adalah kaitan beberapa faktor produksi serta jumlah produk yang dibuat. Faktor produksi pada dasarnya dibedakan mejadi empat golongan, yaitu tanah, kemampuan, modal serta tenaga kerja. sedangkan peranan produksi ialah kemungkinan hasil produksi. Dengan kata lain peranan produksi merupakan peran yang menunjukkan kaitan gabungan bahan-bahan produksi dengan hasil yang diperoleh (produk) yang dimungkinkan untuk produksi. Di dalam teori ekonomi ulasan tentang produksi sering dicontohkan dengan tiga peran produksi yang disebut-sebut yaitu kemampuan berwirausaha, tanah serta modal adalah tetap jumlahnya (Lesmana, 2014).

\section{Investasi}

Investasi ialah suatu kegiatan pengeluaran perusahaan atau pemerintah secara keseluruhan untuk menyediakan bahan-bahan modal baik untuk mendirikan perusahaan baru maupun untuk memperluas usaha yang telah ada dengan maksud supaya mendapatkan keuntungan yang lebih banyak.

\section{Tenaga Kerja}

Tenaga kerja merupakan komponen produksi selain faktor produksi tanah dan modal yang mempunyai peranan penting dalam mendukung kegiatan membuat suatu produk barang atau jasa. Pertambahan permintaan barang dan jasa di masayarakat akan mengakibatkan peningkatan permintaan tenaga kerja. Permintaan ini disebut derived demand, karena berubah nya tenaga kerja yang diminta sebagai input ditentukan oleh perubahan permintaan outputnya (Simanjuntak, 1995).

\section{Penelitian Sebelumnya}

(Agustina \& Kartika, 2017) Pengaruh Tenaga Kerja, Modal dan Bahan Baku Terhadap Produksi Industri Kerajinan Patung Kayu Di Kecamatan Tegalalang. Hasil penelitian menunjukkan tenaga kerja memengaruhi kepada produksi.

Persamaan penelitian ini dengan kajian yang di buat oleh peneliti terdapat pada variabel tenaga kerja dan hasil produksi.

Perbedaan penelitian ini dengan telaah yang akan peneliti dikerjakan yaitu pada analisis. Alat analsis data yang dicantumkan pada kajian sebelumnya adalah program SPSS, sedangkan penelitian yang akan dilakukan oleh peneliti menggunakan program EVIEWS

\section{METODE PENELITIAN Data dan Sumber Data}

Jenis data ialah berbentuk kuantitatif, yaitu data sekunder selama periode 2010-2016 yang diperoleh dari berbagai instansi yang terkait yaitu BPS, Dinas Perindustrian.

\section{Metode Analisis Data Analisis Regresi}

Analisis yang di cantumkan pada kajian ini yaitu regresi linear berganda yang menggunakan metode OLS (Ordinary Least Square). Dengan menggunakan program Eviews 9. Bentuk persamaannya yaitu:

$$
\operatorname{Ln} Y=\alpha+\beta_{1} \operatorname{Ln} X_{1}+\beta_{2} \operatorname{Ln} X_{2}+e
$$

Keterangan:

$$
\begin{array}{ll}
\mathrm{Y} & =\text { Produksi } \\
\alpha & =\text { Konstanta } \\
\beta_{1}, \beta_{2} & =\text { Koefisien Regresi }
\end{array}
$$


Ln $\mathrm{X}_{1}=$ Investasi

Ln $\mathrm{X}_{2}=$ Tenaga Kerja

$\mathrm{e}=$ Error term, yaitu tingkat kesalahan dalam penelitian ini.

\section{HASIL PENELITIAN DAN PEMBAHASAN}

Analisis Regresi

Tabel 1

Hasil Regresi Pengaruh Investasi Dan Tenaga Kerja Terhadap Produksi Industri Kecil Di Kabupaten Aceh Utara

\begin{tabular}{lrrrr}
\hline \hline & Coefficien & & \\
Variable & $\mathrm{t}$ & Std. Error & t-Statistic & Prob. \\
\hline \hline & & & & \\
C & -19.65016 & 3.985788 & -4.930057 & 0.0079 \\
LOG(INVESTASI) & 1.246023 & 0.143005 & 8.713131 & 0.0010 \\
\multicolumn{1}{c}{ LOG(TK) } & 2.188301 & 0.302221 & 7.240722 & 0.0019 \\
\hline \hline & & & & \\
R-squared & 0.959689 & Mean dependent var & 18.71017 \\
Adjusted R-squared & 0.939534 & S.D. dependent var & 1.150435 \\
S.E. of regression & 0.282890 & Akaike info criterion & 0.610013 \\
Sum squared resid & 0.320108 & Schwarz criterion & 0.586832 \\
Log likelihood & 0.864954 & Hannan-Quinn criter. & 0.323496 \\
F-statistic & 47.61455 & Durbin-Watson stat & 1.653957 \\
Prob(F-statistic) & 0.001625 & & \\
\hline \hline
\end{tabular}

Sumber: Hasil Olah Data, 2018

Dari pada tabel 1 diatas maka diperoleh hasil $\log \mathrm{Y}=$ Produksi $=-19,6-1,246$ Investasi $+2,18$ TK yaitu dimana :

Produksi :Apabila Investasi dan Tenaga Kerja konstan maka Produksi -19.6501.

Investasi :Apabila investasi meningkat sebesar 1 persen maka produksi akan meningkat sebesar $1,25 \%$ dan tingkat keyakinan 95\% sisanya $5 \%$ dijelaskan oleh variabel lain diluar penelitian ini.

Tenaga Kerja: Apabila Tenaga Kerja meningkat sebesar 1 persen maka produksi meningkat sebesar $2.19 \%$ pada tingkat keyakinan $95 \%$ dan sisanya $5 \%$ dijelaskan oleh variabel lain diluar penelitian ini.
Hasil Uji Normalitas

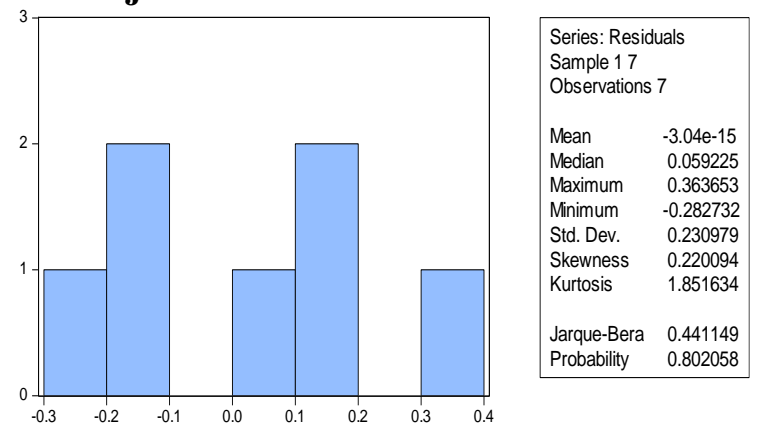

Sumber: Hasil Pengolahan Data 2018

Gambar 1

Uji Normalitas

Dari percobaan yang tampak pada diagram di atas nilai Jarque-Bera adalah sebesar 0,4411, sementara nilai Chi Square dengan melihat jumlah variabel bebas yang kita pakai dalam hal ini 2 variabel bebas dan nilai signifikan yang kita pakai dalam hal ini 0,05 (5\%). Di dapat nilai Chi Squaresebesar 5,9915 yang berarti nilai JarqueBera lebih kecil dari nilai Chi Square $(0,4411<$ 5,9915) dan Probabilitas sebesar 0,802 > 0,05, berarti Investasi, Tenaga Kerja dan Produksi pada industri kecil di Kabupaten Aceh Utara sebesar 0,802 lebih besar dari 0,05, maka dapat disimpulkan bahwa data residual dalam penelitian ini sudah berdistribusi normal.

\section{Hasil Uji Autokorelasi}

Tabel 2

\section{Uji Autokorelasi}

\section{Hasil Uji Breusch-Godfrey Seri \\ Correlation LM Test \\ .Breusch-Godfrey Serial Correli Test:}

$\begin{array}{lcl}\text { F- } & 0.05 & \\ \text { statistic } & 1224 & \text { Prob. F(2,2) } \\ \text { Obs*R- } & 0.34 & \text { Prob. Chi- } \\ \text { squared } & \text { 1093Square(2) }\end{array}$

Sumber: Hasil Olah Data, 2018

Berdasarkan Uji LM Test dari df Chi-Square pada $\alpha=1 \%$ dan $\alpha=5 \%$ masing - masing adalah 9,2104 dan 5,9915. Hasil dari Obs*R-squared adalah sebesar 0,341093 atau 0,341093<5,9915 dan Probabilitas Chi-Squared sebesar 0,8432> 
0,05. Yang berarti bahwa penelitian ini sudah terbebas dari indikasi autokorelasi.

\section{Hasil Uji Multikolonearitas}

Tabel 3

Uji Multikolonearitas

\begin{tabular}{|l|l|l|}
\hline & Tenaga \\
& INVESTASI & \begin{tabular}{l} 
Kerja \\
\hline INVESTASI
\end{tabular} \\
\hline TK & -0.3600000 & -0.360607 \\
\hline
\end{tabular}

Sumber: Hasil Olah Data, 2018

Berdasarkan tabel di atas terlihat bahwa koefisien korelasi sebesar 0.360607 .Hal ini menunjukkan tidak terjadinya multikolinieritas karena koefisien korelasinya lebih kecil dari 0.8.

\section{Hasil Uji Heteroskedastisitas}

Tabel 4

\section{Uji Heteroskedastisitas}

.Heteroskedasticity Test: White

\begin{tabular}{llcr}
\hline \hline & $1.46 \mathrm{E}+$ & & \\
F-statistic & 17 & Prob. F(4,2) & 0.0000 \\
Obs*R- & 7.0000 & Prob. & Chi- \\
squared & 00 & Square(4) & 0.1359 \\
$\begin{array}{l}\text { Scaled } \\
\text { explained SS 96 }\end{array}$ & Square(4) & Chi- \\
& & & \\
& & & \\
\hline \hline
\end{tabular}

Sumber: hasil olah data 2018

Berdasarkan hasil uji white-Test menggunakan program eviews versi 9, dapat dilihat nilai $\mathrm{Obs}^{*} \mathrm{R}$ sebesar 7,00 dengan $\chi^{2}$ dengan df (4) pada $\chi^{2}$ pada tabel $\alpha: 5 \%$ sebesar berdasarkan hasil Obs*R.squared 7,00 $<9,5$ maka dalam penelitian model ini sudah tidak ada indikasi heterosdaktisitas. Hal ini juga dilihat dari probabilitas sebesar $0,1359>0,50$

\section{Pembuktian Hipotesis \\ Hasil Uji Parsial}

Uji statistik merupakan pengujian terhadap koefisien dari variabel bebas secara parsial. Uji dikerjakan demi menampakkan signifikasi dari variabel bebas secara satu-satu ketika mempengaruhi variasi dari variabel dependent. Pengujian ini dibuat dengan upaya membandingkan $t_{\text {statistik }}$ pada hasil regresi dengan $t_{\text {tabel. }}$
1. Jika $t_{\text {hitung }}>\mathrm{t}_{\text {tabel, }}$ pada $\alpha=0.05$ maka $\mathrm{H}_{1}$ diterima berarti variabel bebas secara satusatu mempengaruhi variabel yang dijelaskan dengan relevan.

2. Jika $t_{\text {hitung }}<t_{\text {tabel, }}$ pada $\alpha=0.05$ maka $H_{1}$ ditolak berarti bahwa variabel bebas dengan individual tidak mempengaruhi variabel yang dijelaskan dengan relevan.

Berdasarkan tabel tersebut tampak variabel Investasi memiliki nilai $t_{\text {hitung }}$ sebesar 8.713131 lebih besar dari $t_{\text {tabel }}$ yaitu sebesar 2.13185 dengan tingkat keyakinansebesar $95 \%$ artinya Investasi berpengaruh secara siqnifikan terhadap produksi. Selanjutnya variabel Tenaga Kerja memiliki nilai

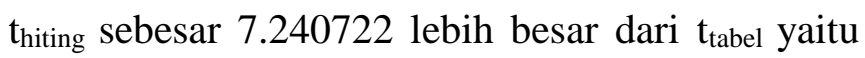
sebesar 2.13185 dengan tingkat keyakinan sebesar 95\% artinya varibel Tenaga Kerja berpengaruh secara siqnifikan terhadap produksi.

\section{Hasil Uji Simultan (Uji F)}

Uji F dilakukan untuk melihat pengaruh variabel independen terhadap variabel terikat dengan bersama - sama membandingkan antara $F_{\text {hitung dengan }} F_{\text {tabel, }}$ apabila $F_{\text {hitung }}>F_{\text {tabel, dengan }}$ cara df $(k-1)(3-1)=2(n-k)=(7-3)=4(2)(4)=6,94$ : jadi variabel Investasi dan tenaga kerja secara bersama-sama berpengaruh signifikan dan positif terhadap produksi karena nilai sebesar 47.61< 6,94. Hal ini juga bisa dilihat dari nilai probabilitas (P-value) sebesar $0.0079<0,05$.

Berdasarkan hasil pengujian yang dibuktikan secara serempak atau bersama - sama dari tabel diatas, maka dapat dilihat nilai $F_{\text {hitungsebesar }}$ 47.6145 lebih besar dari $F_{\text {tabel }}$ yaitu sebesar 6.94, artinya variabel bebas berpengaruh secara bersama - sama terhadap variabel terikat.

\section{Koefisien Determinasi $\left(\mathrm{R}^{2}\right)$ dan Koefisien Korelasi (R)}

\section{Koefisien Determinasi $\left(\mathbf{R}^{\mathbf{2}}\right)$}

Dari hasil pengolahan data R.Squared sebesar 0.939534 jadi besar pengaruh investasi dan tenaga kerja terhadap produksi ialah sebesar $93,95 \%$, sedangkan yang dipengaruhi oleh variabel lain diluar model ini adalah sebesar $5 \%$.

\section{Koefisien Korelasi (R)}

Berdasarkan uji yang telah dilaksanakan diperoleh nilai korelasi $(\mathrm{R})=\sqrt{ } \mathrm{R}^{2}=\sqrt{ } 0.9395=$ 
0,9692. Jadi hubungan variabel investasi, tenaga kerja terhadap produksi berhubungan sangat erat/sangat kuat secara positif, karena nilai 0,9692 mendekati positif satu $(+1)$.

\section{Pembahasan}

Berdasarkan hasil empat pengujian Asumsi Klasik, diketahui bahwa Autokorelasi, Heteroskedastisitas, Multikoliniearitas, dan Uji Normalitas menunjukkan bahwa data dapat dianalisis kedalam persamaan regresi dikarenakan tidak terjadi masalah pada semua Uji Asumsi Klasik. Untuk mengetahui hubungan variabel investasi dan tenaga kerja terhadap produksi tampak dari nilai R. Berdasarkan hasil pengujian ditemukan bahwa nilai $\mathrm{R}$ sebesar 0.939534 yang artinya terjadi hubungan dekat antara variabel Investasi dan Tenaga Kerja terhadap Produksi.

Selanjutnya untuk mengetahui pengaruh dari variabel investasi dan tenaga kerja terhadap produksi pada industri kecil di Kabupaten Aceh Utara dapat dilihat pada nilai $\mathrm{R}^{2}$. Dari hasil pengujian ditemukan bahwa nilai $R^{2}$ sebesar 0.9692956205 yang berarti pengaruh variabel investasi dan tenaga kerja terhadap produksi pada industri kecil di Kabupaten Aceh Utara adalah sebesar 0.9692956205 atau 97\%, sementara sisanya sebesar $3 \%$ dipengaruhi oleh variabel lainnya di luar penelitian ini.

Berdasarkan pengujian secara parsial, dapat disimpulkan bahwa variabel investasi berpengaruh baik dan signifikan terhadap produksi. Hal ini memiliki dengan teori yang menyatakan bahwa semakin banyaknya investasi akan meningkatkan input produksi seperti tenaga kerja, bahan baku, mesin dan sebagainya sehingga akan menyebabkan meningkatnya produksi pada industri kecil.

Berdasarkan pengujian secara parsial dapat disimpulkan bahwa variabel tenga kerja berpengaruh baik dan signifikan terhadap produksi. Hal ini sejalan atau sama dengan kajian yang diciptakan dari (Agustina \& Kartika, 2017) dalam penelitiannya tentang pengaruh tenaga kerja, modal dan bahan baku terhadap output industri kerajinan patung kayu di Kecamatan Tegallalang yang menyatakan tenaga kerja berpengaruh terhadap hasil produksi.

Berdasarkan telaah yang dibuat secara serempak atau bersama -sama dapat disimpulkan bahwa variabel investasi dan tenaga kerja berpengaruh secara simultan terhadap produksi Aceh Utara.

\section{KESIMPULAN DAN SARAN \\ Kesimpulan}

Dari observasi yang telah diselesaikan bisa disimpulkan sebagai berikut :

a. Hasil penelitian secara parsial menunjukkan bahwa Investasi dan Tenaga Kerja berpengaruh bagus dan signifikan terhadap produksi, dan dengan kajian yang dibuat secara serempak atau bersama-sama diketahui bahwa investasi dan tenaga kerja berpengaruh simultan terhadap produksi di Aceh Utara.

b. Investasi pada sector industri kecil formal yang mengalami peningkatan (trend positif) setiap tahunnya tidak memberikan kontribusi besar bagi produksi pada industry kecil di Kabupaten Aceh Utara, seharusnya dengan meningkatnya investasi diikuti oleh peningkatan terhadap tenaga kerja dan akan memberikan kontribusi yang besar terhadap produksi pada industri kecil formal di Aceh Utara.

\section{Saran}

Berdasarkan telaah yang telah diciptakan oleh peneliti terdapat beberapa saran, yaitu :

a. Dengan menggunakan variabel yang sama, penelitian selanjutnya dapat dilakukan pada semua daerah diseluruh Indonesia. Hal ini bertujuan untuk memiliki cakupan yang lebih luas dan tidak hanya sebagian atau kota saja.

b. Bagi Pemerintah Kabupaten Aceh Utara agar dapat lebih memaksimalkan dalam hal produksi pada industri kecil formal di Kabupaten Aceh Utara, dikarenakan semakin banyak produksi yang dihasilkan semoga memperoleh manfaat baik terhadap kemajuan dari segi ekonomi Kabupaten Aceh Utara.

c. Pemerintah seharusnya menggali potensi indutri kecil yang baru serta memaksimal potensi industri yang ada, agar terciptanya lapangan kerja baru sehingga dapat meningkatkan penyerapan tenaga kerja yang 
dapat meningkatkan produksi industri kecil di Aceh Utara.

\section{DAFTAR PUSTAKA}

Abdullah, S. dan A. H. (2003). Pengaruh Dana Alokasi Umum (DAU) dan Pendapatan Asli Daerah (PAD) terhadap Belanja Pemerintah Daerah Studi sampoinit(Simposium). Yogyakarta.

Adisaputro, G. dan Y. A. (2007). Anggaran Bisnis. Yogyakarta: UPP STIM YKPN.

Agustina, (2017). Pengaruh Tenaga Kerja Modal Dan Bahan Baku Terhadap Produksi Industri Kerajinan Patung Kayu Di Kecamatan Tegallalang.E-Jurnal EP UNUD. Universitas Udayana, 6(7), 29. Retrieved from https://ojs.unud.ac.id/index.php/eep/issue/vie w/2299

A., Novianto, T. F., \& Atmanti, H. D. (2013).Pengaruh Investasi dan Tenaga Kerja Terhadap Pertumbuhan PDRB Provinsi Jawa Tengah Tahun 1992-2011, 2, 1-9.

Ginting, (2007). Sistem Produksi dan Perencanaan Pengendalian ProduksiYogyakarta: Graha Ilmu.

Hidayat, M., Hadi, M. F., \& Sutrisno, S. (2017). Analisis Tingkat Partisipasi Angkatan Kerja (Tpak) Perempuan Antar Kabupaten Di Provinsi Riau. Media Trend, 12(1), 76-89. https://doi.org/10.21107/mediatrend.v12i1.25 41

Jhingan, (2000). Ekonomi Pembangunan dan Perencanaan. Jakarta: PT Raja Grafindo Persada.

Mulyadi, (2016). Pengaruh Investasi, Tenaga Kerja Dan Infrastruktur Listrik Terhadap Produksi Sektor Konstruksi Antar Provinsi Di Pulau Jawa Tahun 2009-2014, $1-64$.

Tambunan,(2011). Pengembangan Agro Industri dan Tenaga Kerja Pedesaan di Indonesia.

Makmun danYasin. (2003). Pengaruh Investasi dan Tenaga kerja Terhadap PDB Sektor Pertanian, Jurnal Kajian Ekonomi dan Keuangan., Vol.7 No.3.
Margaretha Elly Silalahi. (2004). Analisis Rencana Perdagangan Indonesia.Indonesia.

Makmun,(2010). Perencanaan Pembangunan Wilayah Dan Keuangan Daerah.Untuk Memenuhi Sebagian Persyaratan Mencapai Derajat Magister Program Studi Magister

Ekonomi dan Studi Pembangunan Konsentrasi:

Irawan,(2013).Investasi Dan Angkatan Kerja Terhadap Pendapatan Asli Daerah Provinsi Jawa Tengah Tahun 2007-2010. Miller, R.I., dan R. E. M. (n.d.). Teori Ekonomi

Mikro Intermediate(Edisi Keti). Jakarta:

PT. Raja Grafindo Persada.

Mulyadi, (2001). Akutansi Manajemen. Jakarta: Salemba Empat.

Nasir, (2011). Analisis Investasi Dan Inflasi Terhadap Pertumbuhan Ekonomi Di Jawa Timur.

Rosyidi, S. (2009). Pengantar Teori Ekonomi. Jakarta: PT. Raja Grafindo Persada.

Simanjuntak, (2005). Manajemen dan Evaluasi Kinerja. Jakarta: FE UI.

Sukirno, S. (2005). Mikro Ekonomi Teori Pengantar(Edisi Keti). Jakarta: Raja Grafindo Persada.

Sukirno, S. (2009). Teori Pengantar Ekonomi mikro. Jakarta: Raja Grafindo Persada.

Jamli, (2012). Tingkat PartisipasiAngkatan Kerja Masyarakat MiskinDi RT.01 R.06 Desa Tegal Gede Kecamatan Sumber Sari Kabupaten Jember. 15-25.

Sunardi Y.P Ratulangi (2017) Pengaruh Pendapatan Asli Daerah (PAD) Dan Tingkat Angkatan Kerja TerhadapPertumbuhan Ekonomi KabupatenDana Bolaang Mongondow Timur, 17(1), 79-86. 